\title{
Globalization of agricultural pollution due to international trade
}

\author{
C. O'Bannon, J. Carr, D. A. Seekell, and P. D'Odorico \\ Department of Environmental Sciences, University of Virginia, Charlottesville, Virginia, USA \\ Correspondence to: P. D’Odorico (paolo@ virginia.edu)
}

Received: 22 July 2013 - Published in Hydrol. Earth Syst. Sci. Discuss.: 27 August 2013

Revised: 2 January 2014 - Accepted: 6 January 2014 - Published: 10 February 2014

\begin{abstract}
Almost $90 \%$ of freshwater resources consumed globally are used to produce plant and animal commodities. Water-scarce countries can balance their water needs by importing food from other countries. This process, known as virtual water transfer, represents the externalization of water use. The volume and geographic reach of virtual water transfers is increasing, but little is known about how these transfers redistribute the environmental costs of agricultural production. The grey water footprint quantifies the environmental costs of virtual water transfers. The grey water footprint is calculated as the amount of water necessary to reduce nitrogen concentrations from fertilizers and pesticides released into streams and aquifers to allowed standards. We reconstructed the global network of virtual grey water transfers for the period 1986-2010 based on international trade data and grey water footprints for 309 commodities. We tracked changes in the structure of the grey water transfer network with network and inequality statistics. Pollution is increasing and is becoming more strongly concentrated in only a handful of countries. The global external grey water footprint, the pollution created by countries outside of their borders, increased $136 \%$ during the period. The extent of externalization of pollution is highly unequal between countries, and most of this inequality is due to differences in social development status. Our results demonstrate a growing globalization of pollution due to virtual water transfers.
\end{abstract}

\section{Introduction}

About $90 \%$ of freshwater used by humans is allocated to agricultural production (Rost et al., 2008; Baron et al., 2002; Hoekstra and Chapagain, 2008). Due to the tight link between water and food, water crises are typically characterized by a lack of sufficient freshwater resources for food production rather than a lack of drinking water (Falkenmark and Rockstrom, 2006). With the populations of some countries already exceeding their carrying capacity (defined by water resources), isolation from the international community may induce water and subsequent food crises (Seekell, 2011; Suweis et al., 2013). However, these countries can balance their water needs by importing plant and animal commodities from other regions. This trade allows countries to "virtually" use water available in other countries (Allan, 1998). This volume of water used during the overall process of production of a commodity is defined as a water footprint (Hoekstra et al., 2011). In this manner, when a commodity is traded between two countries, the water resources associated with the production of that commodity are transferred "virtually" from the exporter to the importer (Chapagain and Hoekstra, 2008; Hoekstra and Chapagain, 2008; Liu and Savenije, 2008; Liu et al., 2007).

Recent analyses of virtual water transfers have revealed both positive and negative impacts. Virtual water transfers favor regional mitigation of water scarcity and food security in overpopulated countries, thereby preventing malnourishment and water wars (Allan, 1998). Virtual water transfers also increase global water-use efficiency because commodities can be produced in regions where production wateruse efficiency is relatively high, then transported to regions where the production water-use efficiency is relatively low (Chapagain et al., 2006; Konar et al., 2012). However, virtual water transfers are not directly related to water scarcity, and empirical analyses find that wealthy countries have disproportionate access to external water resources relative to less wealthy countries (Seekell et al., 2011). Further, virtual water transfers reduce long-term societal resilience to drought, raising important questions about the sustainability of the global trade system from a water resources perspective (D’Odorico et al., 2010). 
Virtual water transfers disconnect populations from the resources they use by creating geographic separation between production and consumption (Carr et al., 2012a, 2013; D'Odorico et al., 2012; Hoekstra and Chapagain, 2008). A consequence of this is consumers might not be directly affected by the environmental degradation resulting from the non-local production of (food) commodities (e.g., soil erosion and pollution from fertilizers and pesticides). In this manner, highly developed countries may be able to externalize pollution disproportionally relative to less developed countries. However, little is known about the global extent and long-term changes in the externalization of pollution through virtual water transfer (Mekonnen and Hoekstra, 2011).

Here, we reconstructed the global network of agricultural pollution based on international trade records and commodity/nation-specific grey water footprints for the period 1986-2010. The grey water footprint, a metric of pollution, is the hypothetical volume of freshwater needed to dilute nitrogen pollution caused by the production of commodities (e.g., Hoekstra and Chapagain, 2008; Mekonnen and Hoekstra, 2011). Countries that import grey water externalize their pollution to countries that export grey water (Fig. 1), while countries that export grey water accumulate pollution within their borders (Fig. 1). Patterns of grey water trade relative to previously described patterns in blue (surface water and ground water) and green (soil water) water transfer (Carr et al., 2012a) were explored. We also examined the contributions of trade to inequality in pollution, in terms of grey water use, and evaluated the role of social development status in influencing that inequality. Our results indicate that the externalization of pollution is increasing and the burden of pollution is being concentrated in a handful of countries.

\section{Methods}

\subsection{Data calculation of grey water footprints}

We reconstructed international grey water transfers for agricultural commodities for the period 1986-2010 using United Nations trade records (FAOSTAT, faostat.fao.org, Supplement) and commodity-specific estimates of grey water footprints based on nitrogen fertilizer use from Mekonnen and Hoekstra (2010, 2011, 2012). These estimates assume that a set fraction of applied nitrogen fertilizer is lost in soil drainage and runoff. We converted live animal weight to "carcass weight" before calculating grey water footprints for live animals. Changes in commodity-specific water footprints were minor during this period (e.g., Sun et al., 2013); hence we assumed that the commodity-specific footprints remain constant over the study period (using estimates based on the period 1996-2005). Political boundary changes during the study period were rectified according to Carr et al. (2013). In this method of analysis, the grey water footprint is a metric

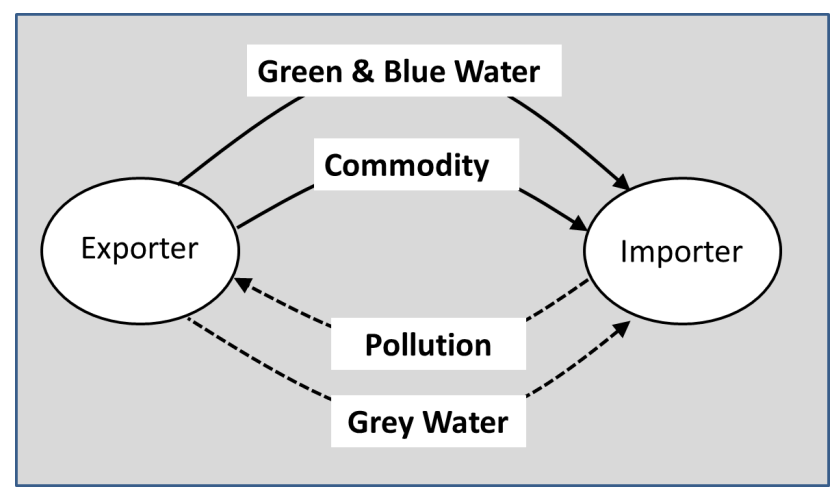

Fig. 1. Green and blue water are virtual water sourced from soil and surface water, respectively. Virtual water goes from exporters to importers in the form of commodities, but the pollution due to production stays in the exporting country. Hence exporters accumulate the pollution of importers and importers externalize their pollution at the expense of the exporters. The dashed arrows for pollution and grey water represent that these are theoretical flows. While not actually being transferred, the avoidance or burden of pollution, and the accumulation or deficit of grey water, are phenomena with real consequences.

of pollution resulting from agricultural production, but is not necessarily an estimate of environmental degradation (Hoekstra et al., 2011; Liu et al., 2012). Regardless, the grey water footprint is useful for understanding the dynamics of the grey water transfer network, and, overall, these methodologies are consistent with recent analyses of blue and green virtual water transfer networks (D'Odorico et al., 2012; Suweis et al., 2013; Carr et al., 2013).

The total grey water footprint of a country $\left(\mathrm{GWF}_{\mathrm{T}}\right)$ was calculated as the sum of the grey water production $\left(\mathrm{GW}_{\mathrm{P}}\right)$ and the net trade of grey water $\left(\mathrm{GWN}_{\mathrm{T}}\right)$, which is equal to the import-export balance between grey water imports $\left(\mathrm{GW}_{\mathrm{I}}\right)$ and grey water exports $\left(\mathrm{GW}_{\mathrm{E}}\right)$.

$\mathrm{GWF}_{\mathrm{T}}=\mathrm{GW}_{\mathrm{P}}+\mathrm{GWN}_{\mathrm{T}}=\mathrm{GW}_{\mathrm{P}}+\mathrm{GW}_{\mathrm{I}}-\mathrm{GW}_{\mathrm{E}}$

Hence, the $\mathrm{GWF}_{\mathrm{T}}$ is comprised of both internal (production - export) and external (import) components. Due to inconsistencies between the trade and production data sets relative to the re-exportation of commodities, roughly nine countries per year $(<0.05 \%$ of the global grey water footprint) had negative total grey water footprints. These nodes and their associated links were removed from the analysis.

\subsection{Statistical analysis}

Complex network analysis was used to analyze variability in the structure of the grey water trade networks (e.g., Konar et al., 2011; Carr et al., 2012b). Each country defines a node in the network, and each trade connection specifies a directed link between nodes (Carr et al., 2012b, 2013). We focused our analysis on the grey water export network because this quantifies the "pollution damage" countries "self-inflict" by 
supplying commodities to other nodes. However, the network statistics for the import network are provided for comparison to previous studies on the virtual (blue + green) water network (Konar et al., 2011; Carr et al., 2012b).

For each year, the degree of each node, calculated as the number of active grey water export links, and the global network degree, the sum of all countries' degrees, were used to describe the level of connectivity in the grey water trade network. Similarly for each year, the individual export strength of each node and the sum of the grey water exports for each country were calculated as the total strength of the export network. The relationship between nodal strength and degree was evaluated by fitting the power-law equation

$s=c k^{a}$

where $s$ is node strength, $k$ node degree, and $c$ and $a$ fit values (Konar et al., 2011). The power exponent is a measure of the concentration of the strength of the network relative to the degree of the nodes. Higher exponents indicate a more concentrated network of grey water trade because nodes with higher degrees have more export links, but each link also has a higher volume of virtual water, on average.

Virtual water transfers may exacerbate or reduce inequalities in water use (Carr et al., 2012a). Inequalities in pollution could be associated with ethical concerns, especially if differences in the burden of pollution are driven by social development factors (Carr et al., 2012a). To this end, we calculated inequality statistics to understand variability in total grey water footprints (e.g., Seekell et al., 2011). Inequality was quantified with the Gini coefficient (Yao, 1999). The Gini coefficient is a standardized inequality metric that ranges from zero (indicating perfect equality; all countries use the same amount of water) to one (indicating perfect inequality; one country uses all of the water). We decomposed Gini coefficients to identify the relative contributions of internal and external grey water use to overall inequality (Yao, 1999; Seekell et al., 2011). Gini coefficient decompositions are analogous to analyses of variance, which partition variance within and between groups. However, the Gini coefficient provides a standardized measure of variance, which facilitates comparisons of inequality between different resource types (e.g., Chen et al., 2010). Large contributions of external use indicate that trade is mostly responsible for inequality, whereas large contributions of internal use indicate that within-country consumption (primarily controlled by geographic factors) accounts for most of the international variability in grey water use (Seekell et al., 2011). We evaluated the contributions of social development status to inequality by grouping countries together based on social development status (defined here by delineating the Human Development Index (HDI) into three classes $0 \leq \mathrm{HDI} \leq 0.5$; $0.5<\mathrm{HDI} \leq 0.8 ; 0.8<\mathrm{HDI} \leq 1)$ and decomposing the Gini coefficient based on these groups (Seekell et al., 2011). The results of the decomposition are measures of the proportional contributions of within- and between-class inequality to the

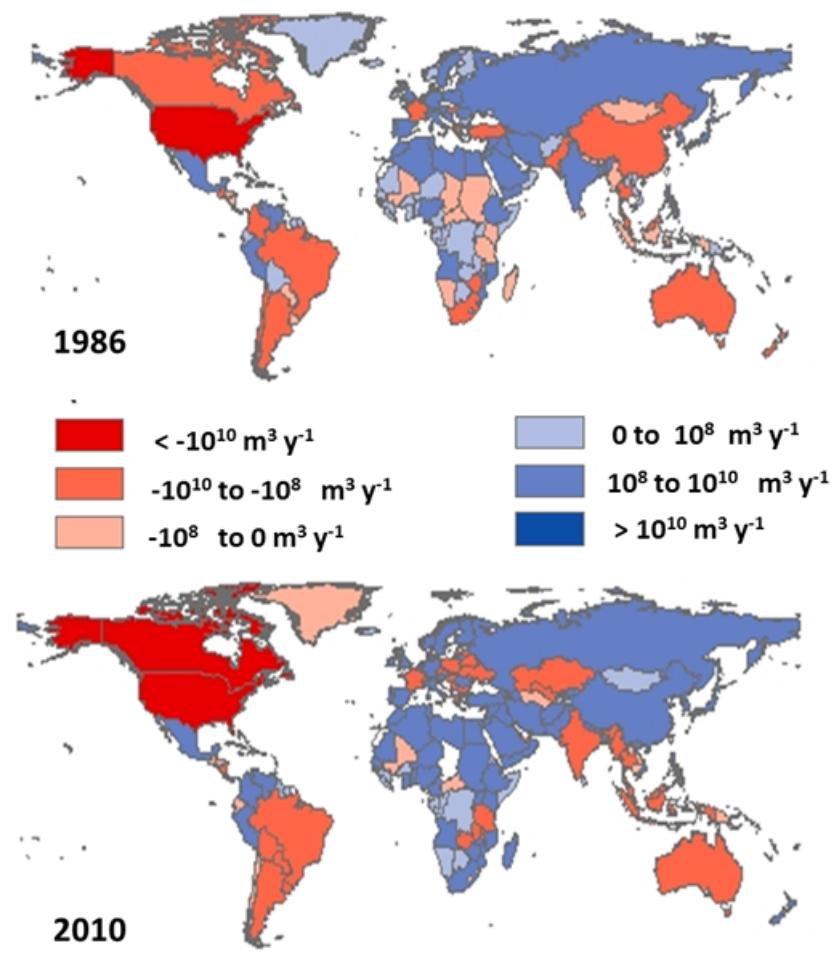

Fig. 2. Net grey water trade (imports-exports in $\mathrm{m}^{3} \mathrm{yr}^{-1}$ ) in 1986 and 2010. The red countries are grey water net exporters, meaning that they are burdened with agricultural pollution from virtual water that was subsequently transferred to other countries. The blue countries are grey water net importers, meaning that they externalize agricultural pollution by importing virtual water from other countries. The identities of large net importers and exporters were relatively static over the $25 \mathrm{yr}$ record. However, countries, such as China, switch.

overall measure of inequality (Table 1) (Yao, 1999). Withinclass inequality is a measure of the inequality in the grey water footprint that occurs between countries within their social development class (low, middle and high), and between-class inequality measures the inequality that exists between the aggregate social development classes. Prior analyses of water footprints found that social development status contributes differently to internal and external water use (see Seekell et al., 2011). As such, this analysis was performed for the years of the study period with both HDI data as well as internal and external grey water footprints. Any countries for which HDI data were not available in a given year were removed from the groupings for that year. 
Table 1. Gini coefficients for total, internal, and external grey water footprints (GWF). $G_{a}$ is the proportion of inequality due to differences within social development classes. $G_{b}$ is the proportion of inequality due to differences between social development classes. $G_{a}$ and $G_{b}$ do not sum to unity because some inequality is caused by overlap between classes (Seekell et al., 2011).

\begin{tabular}{cccccccccc}
\hline & \multicolumn{3}{c}{ Total GWF } & \multicolumn{3}{c}{ Internal GWF } & \multicolumn{3}{c}{ External GWF } \\
\hline Year & Gini & $G_{a}(\%)$ & $G_{b}(\%)$ & Gini & $G_{a}(\%)$ & $G_{b}(\%)$ & Gini & $G_{a}(\%)$ & $G_{b}(\%)$ \\
\hline 1986 & 0.545 & 0.341 & 0.494 & 0.592 & 0.362 & 0.397 & 0.780 & 0.190 & 0.672 \\
1990 & 0.530 & 0.359 & 0.440 & 0.461 & 0.433 & 0.441 & 0.780 & 0.188 & 0.684 \\
2000 & 0.528 & 0.332 & 0.279 & 0.514 & 0.350 & 0.236 & 0.743 & 0.244 & 0.647 \\
2005 & 0.517 & 0.442 & 0.236 & 0.503 & 0.473 & 0.126 & 0.730 & 0.289 & 0.563 \\
2006 & 0.503 & 0.459 & 0.204 & 0.489 & 0.486 & 0.075 & 0.721 & 0.294 & 0.562 \\
2007 & 0.498 & 0.432 & 0.261 & 0.475 & 0.423 & 0.145 & 0.716 & 0.290 & 0.554 \\
2008 & 0.505 & 0.428 & 0.261 & 0.492 & 0.367 & 0.162 & 0.728 & 0.280 & 0.587 \\
2009 & 0.506 & 0.431 & 0.254 & 0.488 & 0.459 & 0.150 & 0.714 & 0.282 & 0.582 \\
2010 & 0.495 & 0.459 & 0.264 & 0.474 & 0.454 & 0.130 & 0.726 & 0.310 & 0.576 \\
\hline
\end{tabular}

\section{Results}

\subsection{Summary results}

The global grey water footprint increased substantially over the record (1.26 trillion $\mathrm{m}^{3} \mathrm{yr}^{-1}$ in 2010 from 790 billion $\mathrm{m}^{3} \mathrm{yr}^{-1}$ in 1986), but the identities of major grey water importers and exporters showed little change (Fig. 2; Table 2). In 1986, the United States was the largest exporter of grey water (approximately 23 billion $\mathrm{m}^{3} \mathrm{yr}^{-1}$ ). Thus, in the perspective here, the United States was accumulating the most agricultural pollution due to virtual water transfers in comparison to other countries. In 1986, Japan was the largest importer of grey water (approximately 9.3 billion $\mathrm{m}^{3} \mathrm{yr}^{-1}$ ), externalizing the most agricultural pollution through virtual water transfers. The United States maintained its position as the largest exporter through 2010 (41 billion $\mathrm{m}^{3} \mathrm{yr}^{-1}$ ). Germany and China were the two largest importers in 2010 (18 and 15 billion $\mathrm{m}^{3} \mathrm{yr}^{-1}$, respectively). The largest grey water transfers were between the Netherlands and Germany (7.49 billion $\mathrm{m}^{3} \mathrm{yr}^{-1}$ ), the United States and Mexico (5.34 billion $\mathrm{m}^{3} \mathrm{yr}^{-1}$ ), and the United States and Japan (5.10 billion $\left.\mathrm{m}^{3} \mathrm{yr}^{-1}\right)$. In total, the volume of grey water externalized through trade in 2010 was 239 billion $\mathrm{m}^{3} \mathrm{yr}^{-1}$.

In 1986, China had the largest total grey water footprint (166 billion $\mathrm{m}^{3} \mathrm{yr}^{-1}$ ), equal to roughly $21 \%$ of the global grey water footprint ( 793 billion $\mathrm{m}^{3} \mathrm{yr}^{-1}$ ) for that year. However, China's average per capita GWF (152 $\mathrm{m}^{3} \mathrm{yr}^{-1} /$ person) was smaller than many countries in the western Hemisphere (Fig. 3). In 2010, China maintained the largest total grey water footprint (386 billion $\mathrm{m}^{3} \mathrm{yr}^{-1}$ ) equal to $31 \%$ of the global grey water footprint. China's per capita grey water footprint was substantially higher in $2010\left(293 \mathrm{~m}^{3} \mathrm{yr}^{-1}\right)$ than in 1986 $\left(152 \mathrm{~m}^{3} \mathrm{yr}^{-1}\right)$, but was still lower than western countries (Fig. 3).
Table 2. Top net importers and net exporters of grey water (billion $\mathrm{m}^{3} \mathrm{yr}^{-1}$ ) in 1986 and 2010.

\begin{tabular}{lclc}
\hline Net importers & \multicolumn{3}{l}{} \\
\hline 1986 & Volume of GW & 2010 & Volume of GW \\
\hline Japan & 9.06 & Japan & 9.43 \\
Italy & 5.69 & Italy & 8.69 \\
USSR & 5.29 & China & 6.92 \\
Germany & 3.30 & Iran & 6.27 \\
Egypt & 2.11 & Germany & 5.91 \\
\hline Net exporters & & & \\
\hline 1986 & Volume of GW & 2010 & Volume of GW \\
\hline United States & -18.0 & United States & -30.2 \\
Canada & -6.26 & Canada & -12.3 \\
Greece & -3.70 & Netherlands & -12.2 \\
Australia & -3.62 & Slovenia & -4.92 \\
China & -2.43 & Brazil & -4.72 \\
\hline
\end{tabular}

\subsection{Network analysis results}

Global food trade intensified substantially over the $25 \mathrm{yr}$ record, both in terms of the number of active trade links and the overall strength of the nodes (Fig. 4). There were 205 active trading nodes (countries) and 8644 active trading links in 1986. By 2010, the number of active trading links increased by $70 \%$ to 14669 , but the number of active nodes remained roughly the same (208). The total strength of the network (i.e., the sum of all fluxes in the network) increased by $136 \%$ (Fig. 4). The average strength per trade link also increased over this time period from 11.7 million $\mathrm{m}^{3} \mathrm{yr}^{-1}$ to 16.3 million $\mathrm{m}^{3} \mathrm{yr}^{-1}$. These results indicate that the global food trade network became more connected during the period 1986-2010 (Fig. 4). These changes parallel previously reported long-term trends in total (green + blue) virtual water trade networks (Carr et al., 2012a), which showed a $92 \%$ increase in the number of active trading links and a doubling 

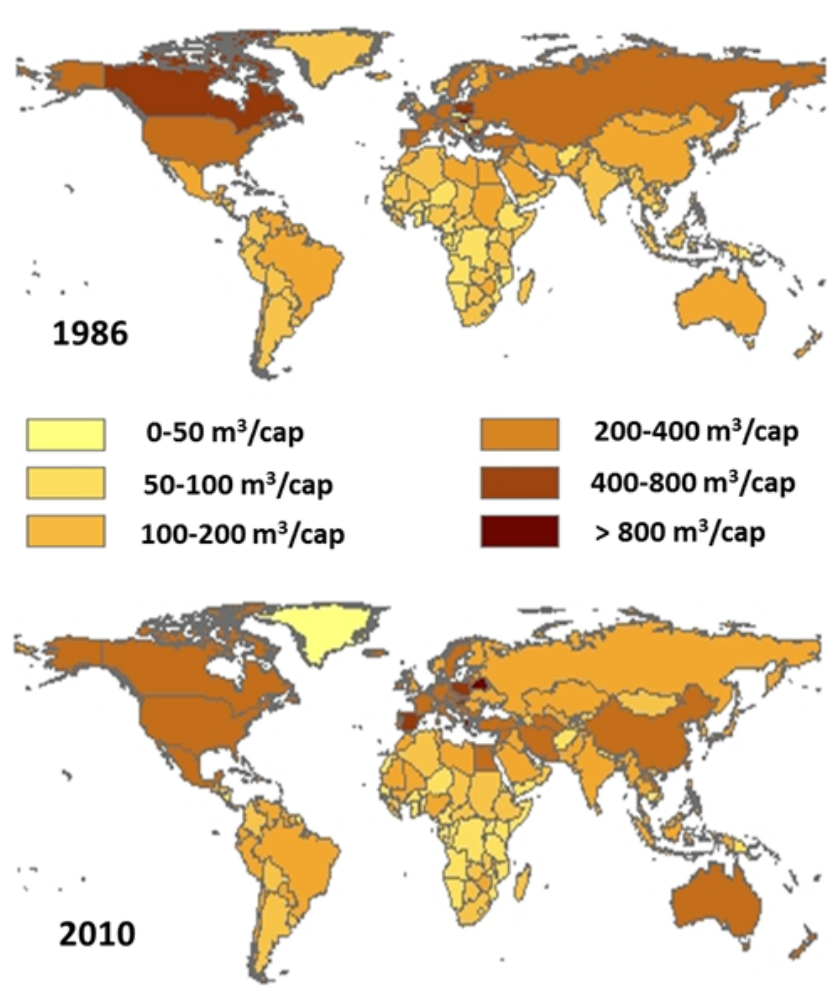

Fig. 3. National grey water footprints (per capita) in 1986 and 2010.

of network strength, with only a small change in number of active nodes.

For the grey water export network, the scaling exponent for the strength-degree power-law equation fluctuated about a mean of 2.52 (standard deviation $=0.11)$. The scaling exponent for the import network had a mean of 2.70 (standard deviation $=0.10$ ). There was no discernible trend in the exponents, and the scaling exponent for the import network is consistently higher than the scaling exponent for the export network. The high exponents (i.e., $>1$ ) show that the average strength of trade links connected to countries with a large number of trade partners is greater than for countries with fewer trade partners. This finding indicates that the global food trade network is concentrated in a few very well connected countries ("hubs"), and its grey water flows are not spread out amongst many nations with fewer links (Konar et al., 2012). The higher exponent for imports rather than exports indicates that as countries increase their number of trade partners, on average, they externalize their pollution at a faster rate than they subject themselves to pollution due to internal production (cf. Konar et al., 2012).

\subsection{Inequality analysis results}

The Gini coefficient for the total grey water footprint varied between 0.50 and 0.55 (mean $=0.51$ ). The Gini coefficient decreased during the study period due to changes in inequality in the internal grey water footprint, but this change
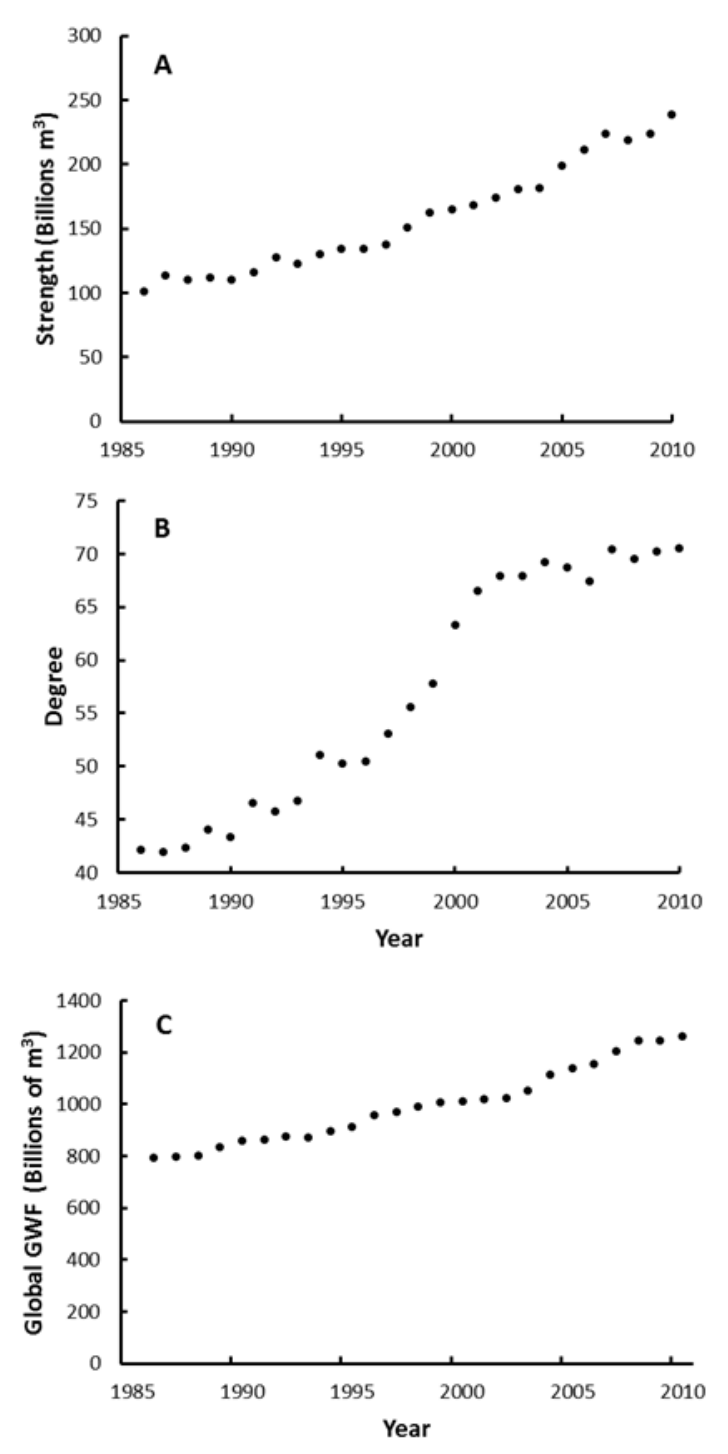

Fig. 4. (A) The total strength $\left(\mathrm{m}^{3} \mathrm{yr}^{-1}\right)$ of the global grey water trade increased over the $25 \mathrm{yr}$ period. (B) The average nodal degree in the network increased over the $25 \mathrm{yr}$ period. (C) The global total grey water footprint increased over the $25 \mathrm{yr}$ period.

was small relative to the overall magnitude of inequality (Table 1). These grey water Gini coefficients are twice the previously reported values $(0.226)$ for total (blue + green) water footprints (Seekell et al., 2011). External grey water footprints were highly unequal (mean Gini coefficient $=0.74$ ), but only accounted for $14.1 \%$ of the inequality in the total grey water footprint because external water footprints are small compared internal water footprints and internal grey water footprints had lower inequality (mean Gini coefficient $=0.50$ ). Internal grey water footprints accounted for an average of $85.9 \%$ of the inequality in the total grey water footprint. In other words, agricultural commodities produced and consumed within a country account for most of the inequality in agricultural pollution between countries. 
In 1986, differences in social development status accounted for $49 \%$ of inequality in the total grey water footprint. This decreased substantially over time, and by 2010 differences in social development status only accounted for $26 \%$ of inequality in the total grey water footprint. This change is mainly due to changes in internal grey water footprint inequality. Differences in social development status accounted for $40 \%$ of inequality in internal footprints in 1986, but this decreased to only $13 \%$ in 2010 . In contrast, social development status accounts for the largest portion of inequality in the external grey water footprint $(60 \%$, on average). The most developed nations had, on average, the highest external grey water footprints.

\section{Discussion}

The externalization of pollution due to agricultural production is pervasive globally, and grey water network strength increased considerably during the study period (1986-2010; Fig. 4). This is a general result of the intensification of international trade and is consistent with previous reports of blue and green virtual water transfers during the same period (e.g., Carr et al., 2012a). As a consequence, grey water transfers will likely increase with projected increases in virtual water transfers (Dalin et al., 2012; Suweis et al., 2011). Our analysis extends these previous results by making the first descriptions of the structure and dynamics of the grey water transfer network, as well as the first measurements of inequality in grey water use.

The internal grey water footprint accounts for the majority of the inequality in grey water distribution among countries relative to the external grey water footprint. However, the external grey water footprint associated with the transfer of grey water among countries is important both because of the ongoing increase in the volume of grey water trade and because of the strong inequalities existing in the external grey water footprint among countries. This inequality exists because socioeconomic differences among countries create unequal abilities to externalize agricultural pollution (Seekell et al., 2011). Over time, this may result in a scenario where wealthy countries disproportionally pollute others because they have a greater access to international trade and, therefore, a greater ability to externalize their pollution; while less wealthy countries face the opposite scenario. Understanding the dynamics of the grey water transfer network is critical to understanding the potential fairness issues associated with this type of inequality.

The substantial between-class inequality in the external grey water footprint (Table 1) indicates that social development status contributes to inequality in the externalization of pollution. Specifically, highly developed countries have the highest per capita externalization of pollution, and the least developed countries have the lowest. Our scaling analyses revealed that more highly connected countries external- ize pollution at a greater rate than they accumulate pollution. More highly developed and connected countries likely increase their imports of luxury animal products, which are associated with higher grey water footprints. Hence the differences in network structure are likely due to differences in the consumptive patterns associated with changes in wealth (cf. Carr et al., 2013). This pattern has some exceptions; for instance, the United States is a highly developed country and is the largest exporter of grey water. However, the United States also offshores a significant amount of agricultural pollution (it is one of the top four importers of grey water, and was the most connected country in the global network of food trade in 2010).

Our results prompt ethical and social questions. For instance, differences in development status could lead to concerns that less developed countries are unfairly targeted with pollution, and while the role of development status in influencing ethical concerns is complex, is it okay for the more developed countries to externalize their pollution disproportionally? In terms of externalizing pollution, the answer is in part context dependent, because water resources are unequal in distribution naturally, and because some regions are likely to have a greater capacity to buffer pollution than others (Seekell, 2011; Liu et al., 2012; Ridoutt and Huang, 2012). Also, virtual water (blue + green water) transfers are generally not an explicit consideration in trade decisions (Allen, 1998). Hence, it is likely that grey water is not directly considered as well. Further, if the situation were reversed, would there still be an ethical concern related to development status? While measures of inequality are typically made relative to hypothetical cases of complete equality, it is not clear if an equal distribution is a necessary goal in terms of environmental justice. For instance, Craswell et al. (2010) evaluated phosphorus transfers from the perspective that redistributing phosphorus will allow for greater production of agricultural goods. Craswell et al. (2010) considered phosphorus as a necessary but sometimes scarce resource (as opposed to a pollutant), changing the ethical concerns related to offshoring - not enough offshoring may reduce food security in phosphorus-poor countries. Judging the relative merits of these perspectives from a fairness point of view is beyond the scope of our quantitative analysis; however emerging sociohydrological studies, such as ours, stand to contribute the quantitative results necessary to inform these more philosophical discussions of global water management and food security.

Our estimate for the total grey water footprint (approximately 1010 million $\mathrm{m}^{3} \mathrm{yr}^{-1}$ on average over the period 1996-2005) is larger than the previously reported estimate by Mekonnen and Hoekstra (2012). This difference is likely due to different trade databases. Despite this difference, grey water footprints are still conservative metrics of pollution as they were estimated based only on nitrogen runoff (Mekonnen and Hoekstra, 2010, 2011) and do not account for other pollutants. For example, while nitrogen pollution is 
important for coastal systems, phosphorus is typically considered the key nutrient in degrading of inland surface water resources and is not accounted for in this analysis (Carpenter and Bennett, 2011). Nonetheless, the results here are useful as a first step in illustrating the extent and structure of the global trade network and externalization of pollution.

In conclusion, the water resource degradation associated with the production and trade of agricultural commodities has been estimated by using the concept of a grey water footprint in order to examine effects of globalization and differences in social development status on the accumulation of pollution. As population and demand for food have increased globally, so has the pollution due to agricultural food production. Moreover, trade provides a mechanism that, while allowing for virtual access to the water resources of a trade partner, directly leads to the externalization of pollution. As a result, consumers are not completely affected by the environmental impacts of their choices, and they may not feel the need to adopt environmentally responsible consumer behaviors voluntarily. In this sense the externalization of pollution through grey water trade may lead to a loss of environmental stewardship. Importantly, differences in social development status are the source of most of the inequality in the externalization of pollution, raising potential ethical concerns. These ethical questions cannot be answered with quantitative analysis alone, and development of a social and philosophical understanding of water issues at the global scale stands to enrich our collective understanding of global water resource issues.

\section{Supplementary material related to this article is available online at http://www.hydrol-earth-syst-sci.net/ 18/503/2014/hess-18-503-2014-supplement.pdf.}

Acknowledgements. This manuscript is based on research supported by the University of Virginia.

Edited by: M. Sivapalan

\section{References}

Allan, J. A.: Virtual Water: A Strategic Resource. Global to regional deficits, Ground Water, 36, 545-546, 1998.

Baron, J. S., Poff, N. L., Angermeier, P. L., Dahm, C. N., Gleick, P. H., Hairston, N. G., Jackson, R. B., Johnston, C. A., Richter, B. D., and Steinman, A. D.: Meeting ecological and societal needs for freshwater, Ecol. Appl., 12, 1247-1260, 2002.

Carpenter, S. R. and Bennett, E. M.: Reconsideration of the planetary boundary for phosphorus, Environ. Res. Lett., 6, 014009 , doi:10.1088/1748-9326/6/1/014009, 2011.
Carr, J. A., D’Odorico, P., Laio, F., Ridolfi, L., and Seekell, D.: Inequalities in the Networks of Virtual Water Flow, EOS T. Am. Geophys. Un., 93, 309-310, 2012a.

Carr, J. A., D’Odorico, P., Laio, F., and Ridolfi, L.: On the temporal variability of the virtual water network, Geophys. Res. Lett., 39, L06404, doi:10.1029/2012GL051247, 2012b.

Carr, J. A., D’Odorico, P., Laio, F., and Ridolfi, L.: Recent History and geography of the virtual water trade, PLoS ONE 8, e55825, doi:10.1371/journal.pone.0055825, 2013.

Chapagain, A. K. and Hoekstra, A. Y.: The global component of freshwater demand and supply: An assessment of virtual water flows between nations as a result of trade in agricultural and industrial products, Water Int., 33, 19-32, 2008.

Chapagain, A. K., Hoekstra, A. Y., and Savenije, H. H. G.: Water saving through international trade of agricultural products, Hydrol. Earth Syst. Sci., 10, 455-468, doi:10.5194/hess-10- 4552006, 2006.

Chen, D., Ma, X., Mu, H., and Li, P.: The inequality of natural resources consumption and its relationship with the social development level based on the ecological footprint and the HDI, J. Environ. Assess. Policy Manag., 12, 69-86, 2010.

Craswell, E. T., Vlek, P. L. G., and Tiessen, H.: Peak-phosphorous - implications for soil productivity and global food security, in: Proceedings of the 19th World Congress of Soil Science: Soil solutions for a changing world, Brisbane, Australia, 1-6 August 2010, Symposium 4.2.1 Soil, Energy and Food Security, 27-30, 2010.

Dalin, C., Konar, M., Hanasaki, N., Rinaldo, A., and RodriguezIturbe, I.: Evolution of the global virtual water trade network, P. Natl. Acad. Sci. USA, 109, 5989-5994, 2012.

D’Odorico, P., Laio, F., and Ridolfi, L.: Does globalization of water reduce societal resilience to drought?, Geophys. Res. Lett., 37, L13403, doi:10.1029/2010GL043167, 2010.

D’Odorico, P., Carr, J., Laio, F., and Ridolfi, L.: Spatial organization and drivers of the virtual water trade: A community-structure analysis, Environ. Res. Lett., 7, 034007, doi:10.1088/17489326/7/3/034007, 2012.

Falkenmark, M. and Rockstrom, J.: The new blue and green water paradigm: Breaking new ground for water resources planning and management, J. Water Res. Pl.-ASCE, 132, 129- 132, 2006.

Food and Agriculture Organization (FAO): FAOSTAT, available at: http://faostat.fao.org (last access: December 2012), 2012.

Hoekstra, A. Y. and Chapagain, A. K.: Globalization of water: sharing the planet's freshwater resources, Blackwell Publishing, Oxford, UK, 2008.

Hoekstra, A. Y., Chapagain, A. K., Aldaya, M. M., and Mekonnen, M. M.: The water footprint assessment manual: Setting the global standard, Earthscan, London, UK, 2011.

Konar, M., Dalin, C., Suweis, S., Hanasaki, N., Rinaoldo, A., and Rodreguez-Iturbe, I.: Water for food? The global virtual water trade network, Water Resour. Res., 47, W05520, doi:10.1029/2010WR010307, 2011.

Konar, M., Dalin, D., Hanasaki, N., Rinaldo, A., and RodriguezIturbe, I.: Temporal dynamics of blue and green virtual water trade networks, Water Resour. Res., 48, W07509, doi:10.1029/2012WR011959, 2012. 
Liu, C., Hoekstra, A. Y., and Gerbens-Leenes, W.: Past and future trends in grey water footprints of anthropogenic nitrogen and phosphorus inputs to major world rivers, Ecol. Indic., 18, 42-49, 2012.

Liu, J. and Savenije, H. H. G.: Time to break the silence around virtual-water imports, Nature, 453, p. 587, 2008.

Liu, J., Zehnder, A. J. B., and Yang, H.: Historical trends in China's virtual water trade, Water Int., 32, 78-90, 2007.

Mekonnen, M. M. and Hoekstra, A. Y.: The green, blue, and grey water footprint of farm animals and animal products, IHE Delft, Delft, the Netherlands, 2010.

Mekonnen, M. M. and Hoekstra, A. Y.: The green, blue and grey water footprint of crops and derived crop products, Hydrol. Earth Syst. Sci., 15, 1577-1600, doi:10.5194/hess-15-15772011, 2011.

Mekonnen, M. M. and Hoekstra, A. Y.: A global assessment of the water footprint of farm animal products, Ecosystems, 15, 401415, doi:10.1007/s10021-011-9517-8, 2012.

Ridoutt, B. G. and Huang, J.: Environmental relevance - the key to understanding water foot- prints, Proc. Natl. Acad. Sci. USA, 109, E1424, doi:10.1073/pnas.1203809109, 2012.

Rost, S., Gerten, D., Bondeau, A., Lucht, W., Rohwer, J., and Schaphoff, S.: Agriculture green and blue water consumption and its influence on the global water system, Water Resour. Res., 44, W09405, doi:10.1029/2007WR006331, 2008.
Seekell, D. A.: Does the global trade of virtual water reduce inequality in freshwater resource allocation?, Soc. Natur. Resour., 24, 1209-1215, 2011.

Seekell, D. A., D'Odorico, P., and Pace, M. L.: Virtual water transfers unlikely to redress inequality in global water use, Environ. Res. Lett., 6, 024017, doi:10.1088/1748-9326/6/2/024017, 2011.

Sun, S. K., Wu, P. T., Wang, Y. B., and Zhao, X. N.: Temporal variability of water footprint for maize production: The case of Beijing from 1978 to 2008, Water Resour. Manage., 27, 2447-2463, 2013.

Suweis, S., Konar, M., Dalin, C., Hanasaki, N., Rinaldo, A., and Rodriguez-Iturbe, I.: Structure and controls of the global virtual water trade network, Geophys. Res. Lett., 38, L10403, doi:10.1029/2011GL046837, 2011.

Suweis, S., Rinaldo, A., Maritan, A., and D'Odorico, P.: Watercontrolled wealth of nations, Proc. Natl. Acad. Sci. USA, 110, 4230-4233, 2013.

Yao, S.: On the decomposition of Gini coefficients by population class and income source: a spreadsheet approach and application, Appl. Econ., 31, 1249-1264, 1999. 